\title{
Magnesium sulfate therapy of preeclampsia: an old tool with new mechanism of action and prospect in management and prophylaxis
}

\begin{abstract}
Aida A Korish
A disturbed balance between angiogenic and antiangiogenic growth factors is a highly accepted mechanism in the pathogenesis of pregnancy-induced hypertension and proteinuria, which is clinically known as preeclampsia (PE). We investigated the effect of magnesium sulfate $\left(\mathrm{MgSO}_{4}\right)$ therapy on vascular endothelial growth factor (VEGF), placental growth factor (PIGF), nitric oxide (NO) metabolites, soluble fm-like tyrosine kinase-1 (sFlt-1) and endoglin levels in PE rats and the effect of this treatment on the feto-maternal outcome. The PE group showed hypertension, proteinuria and decreased number and weight of live pups relative to the control group. This result was associated with increased sFIt-1, VEGF receptor-2 (VEGFR-2), VEGFR-3 and endoglin levels but decreased $\mathrm{NO}$ metabolites. $\mathrm{MgSO}_{4}$ therapy ameliorated systolic hypertension and proteinuria and decreased sFIt-1, VEGFR-2, VEGFR-3 and endoglin levels but increased NO metabolites in the treated group. Physiological and biochemical changes and improved pup weight and viability were observed in the treated group. The vasodilator action of $\mathrm{MgSO}_{4}$ and increased NO production are expected to increase placental blood flow and help fetal nutrition and development. Relief of placental ischemia decreases the production of antiangiogenic growth factors and restores the bioavailability of angiogenic factors (PIGF and VEGF). These changes resulted in better fetal outcome and an improved clinical picture of PE. These findings are promising and encourage further study of the mechanism of action of $\mathrm{MgSO}_{4}$ to support its widespread use in the prevention and management of the etiopathological changes underlying the vast majority of the manifestations and complications of PE.
\end{abstract}

Hypertension Research (2012) 35, 1005-1011; doi:10.1038/hr.2012.103; published online 5 July 2012

Keywords: angiogenic-antiangiogenic growth factors; endoglin; magnesium sulfate therapy; preeclampsia; soluble fm-like tyrosine kinase-1

\section{INTRODUCTION}

Preeclampsia (PE) is a well-documented pregnancy-specific syndrome that complicates $5-8 \%$ of pregnancies in developed countries, reaching double this ratio in developing countries and causing 50000-75000 (15\%) maternal deaths worldwide per year. ${ }^{1-3}$ Changes in proangiogenic and antiangiogenic factors are reported in preeclamptic pregnancies, and the disturbance in their levels is considered the main cause of the endothelial dysfunction that underlies the rest of the pathophysiological alterations of the disease. $^{4,5}$ Placental ischemia and hypoperfusion are common findings in PE. ${ }^{6,7}$ They decrease placental growth factor (PlGF) and produce high concentrations of circulating antiangiogenic factors, such as soluble vascular endothelial growth factor receptor-1 (sVEGFR-1), known as soluble fm-like tyrosine kinase-1 (sFlt-1), and the transmembrane glycoprotein endoglin (ENG).,6,7 Increased sFlt-1 and ENG production has been reported before the onset of the clinical picture of PE. ${ }^{6}$ This report supports the hypothesis that these factors are a cause and not only a result of the endothelial dysfunction in the major body organs, causing proteinuria, hypertension and the rest of the systemic manifestations of the disease. ${ }^{8,9}$ VEGF has been reported to augment nitric oxide (NO) production through VEGFR-2/ the kinase domain receptor, ${ }^{10}$ and $\mathrm{NO}$ was found to have an important role in the mitogenic effect of VEGF during angiogenesis. ${ }^{11}$ However, little is known about the relation between circulating VEGF and NO levels in PE. Decreased NO leads to vasospasm and hypoxia, which changes VEGF levels. ${ }^{12}$ In addition to increased lipid peroxides and impaired antioxidant defense mechanisms, these changes may have a role in the etiology of PE. ${ }^{12}$

Magnesium sulfate $\left(\mathrm{MgSO}_{4}\right)$ is used in the management of severe cases of $\mathrm{PE}$ to prevent the progression to eclampsia. ${ }^{13}$ However, despite its low cost and clear evidence of multiple beneficial effects in the $\mathrm{PE}$ syndrome, the use of $\mathrm{MgSO}_{4}$ is still below the expected level in several countries, and the mechanism of action of this drug, particularly its effect on the angiogenic factors that regulate endothelial function and new blood vessel formation, in pregnancy is still unclear. We hypothesized that normalizing the balance between 
circulating angiogenic and antiangiogenic growth factors in PE may halt the progression of the disease and improve the chances of healthy outcome for the pregnant mothers and their fetuses. In the current study, we investigated the effect of $\mathrm{MgSO}_{4}$ treatment on balancing angiogenic (VEGF, PlGF and NO) and antiangiogenic (sFlt-1 and ENG) growth factors and the effect of this treatment on the clinical manifestations and pregnancy outcome in PE rats.

\section{METHODS}

\section{Experimental design}

The study protocol was approved by the local ethics committee, and the experimental procedures were in accordance with the Guide for Care and Use of Laboratory Animals of the National Institutes of Health. All of the animals were maintained under standard laboratory conditions on a 12-h light/dark cycle with free access to food and water ad libitum. Virgin Wistar rats bred in the Laboratory Animal Care Unit of the College of Medicine, King Saud University, were caged 1:1 with mature males for mating. For confirmation of pregnancy, vaginal smears were checked in the early morning under a light microscope. The day of presence of spermatozoa was designated as day 0 of the 21-22-day gestation period. On day 13 of pregnancy, 60 pregnant and 10 nonpregnant rats $(250-270 \mathrm{~g})$ were randomized into the following experimental groups:

CON-NP: control non-pregnant rats with no treatment $(n=10)$.

CON-P: control pregnant rats with no treatment $(n=20)$.

PRE: pregnant rats with PE receiving no treatment $(n=20)$.

$\mathrm{PRE}+\mathrm{MgSO}_{4}$ : pregnant rats with $\mathrm{PE}$ treated with $\mathrm{MgSO}_{4}(n=20)$.

\section{Induction of $\mathrm{PE}$ and treatment}

Omega nitro-L-arginine methyl ester (L-NAME) was administered orally at a dose of $60 \mathrm{mg} \mathrm{kg}^{-1}$ per day to induce PE in PRE and PRE $+\mathrm{MgSO}_{4}$ groups beginning at day 13 of pregnancy through term. ${ }^{14}$ From day 17 of pregnancy to day 21 (Term), the PRE $+\mathrm{MgSO}_{4}$ group received $500 \mathrm{mg} \mathrm{kg}^{-1}$ per day $\mathrm{MgSO}_{4}$ through s.c. osmotic mini pumps (Model $2 \mathrm{ml}$, Alzet Corp, Palo Alto, CA, USA). ${ }^{15}$ The CON-P group received saline infusion. L-NAME and $\mathrm{MgSO}_{4}$ powders were purchased from Sigma Chemical (St Louis, MO, USA). ELISA kits for mouse sFlt-1 (sVEGFR-1), VEGFR-2, rat VEGF, PlGF and nitrate/nitrite $\left(\mathrm{NO}_{2}{ }^{-} / \mathrm{NO}_{3}{ }^{-}\right)$were purchased from R\&D Systems (Minneapolis, MN, USA). The ELISA kits for VEGFR-3 (Flt-4) and endoglin were purchased from USCN Life Science Inc (Missouri City, TX, USA). Colorimetric kits for urine protein and serum magnesium determination were purchased from Spinreact (Girona, Spain) and United Diagnostics Industry (Riyadh, Saudi Arabia), respectively.

\section{Blood pressure (BP) measurement and sampling}

Systolic BP was measured in all of the studied groups at days 0 and 20 of pregnancy with the non-invasive blood pressure system (NIBP) using tail-cuff plethysmography (Letica LE 5100, Panlab, Barcelona, Spain). Urine samples were collected at days 0 and 20 of pregnancy. Blood samples were collected at day 19 of pregnancy from the retro-orbital plexus in plain test tubes. At full-term (day 21 of pregnancy), animals were weighed and anesthetized with intramuscular (IM) ketamine $\left(40 \mathrm{mg} \mathrm{kg}^{-1}\right.$ body wt) and xylazine $\left(5 \mathrm{mg} \mathrm{kg}^{-1}\right.$ body $\mathrm{wt}$ ), and intracardiac blood sampling and midline laparotomy incision were performed to expose the uterine horns. The developed fetuses were counted and removed. After delivery of the pups, their weight and condition (dead or alive) were recorded. One kidney was isolated from each rat, washed with cold saline, immediately immersed in $10 \%$ neutral-buffered formalin and reserved for histopathological examination.

\section{Biochemical analysis}

Proteinuria, NO production and serum magnesium level. Protein loss in the urine was quantified by a protein assay kit (Spinreact, Girona, Spain) according to the manufacturer's instructions. Total NO production was evaluated by measuring the stable end products of NO metabolism (nitrate and nitrites) in serum and urine with a special kit (R\&D Laboratories, Minneopolis, MN, USA) using nitrate reductase and Griess reagents with an ELISA reader. ${ }^{16}$ The mean minimum detection limit was $0.25 \mu$ moll ${ }^{-1}$. Total serum magnesium $\left(\mathrm{Mg}^{++}\right)$concentration was measured colorimetrically using the calmagite complexometric method according to the kit manufacturer's instructions.

\section{Serum VEGF, sVEGFR-1, VEGF-2, VEGF-3, PlGF and ENG levels}

Generally, these assays employed the quantitative sandwich enzyme immunoassay technique. ${ }^{17}$ The mean minimum detection limit of VEGF, PIGF and VEGFR-2 was $8.5 \mathrm{pg} \mathrm{ml}^{-1}, 7 \mathrm{pg} \mathrm{ml}^{-1}$ and $0.27 \mathrm{ng} \mathrm{ml}^{-1}$, respectively, and the detection limits for sFlt-1, VEGFR-3 and Endoglin were $0-8000 \mathrm{pg} \mathrm{ml}^{-1}$, $31.2-2000 \mathrm{pg} \mathrm{ml}^{-1}$ and $0.78-50 \mathrm{ng} \mathrm{ml}^{-1}$, respectively.

\section{Histopathological examination}

The fixed kidney tissue samples were embedded in paraffin, cut into $3-5-\mu \mathrm{m}$ sections, stained with hematoxylin and eosin and examined under an Olympus BX51 microscope and DP72 Camera (12 MG Pixel).

\section{Statistical analysis}

Data were analyzed using the computer software SPSS 17.0 (SPSS, Inc., Chicago, IL, USA) package for Windows. The comparison between several groups was performed using a one-way analysis of variance. A post-hoc least significant difference (LSD) test was used when analysis of variance showed significant differences. The comparison between samples of the same group at different time points of the study was performed by paired sample $t$-test. Pearson's correlation analysis was used to study the relation between two variables. Data are presented as the mean \pm s.d. The results were significant at $P<0.05$.

\section{RESULTS}

\section{Systolic BP}

At day 20 of pregnancy, the PRE group showed significantly higher BP relative to the CON-P group $(P<0.001) . \mathrm{MgSO}_{4}$ significantly decreased the $\mathrm{BP}$ of the $\mathrm{PRE}+\mathrm{MgSO}_{4}$ group in comparison with the non-treated PRE group $(P<0.001)$, but BP remained significantly higher than the control value $(P<0.001)$ (Table 1$)$.

\section{Proteinuria}

Table 1 shows that by day 20 of pregnancy, proteinuria was significantly higher in the PRE group in comparison with the CON-P group $(P<0.001) . \mathrm{MgSO}_{4}$ treatment significantly decreased the proteinuria in the $\mathrm{PRE}+\mathrm{MgSO}_{4}$ group compared with the PRE group $(P<0.001)$, but it remained significantly higher than the CON$\mathrm{P}$ and CON-NP groups $(P<0.001$ for each).

\section{NO production}

$\mathrm{PE}$ caused a significant decrease in serum and urinary $\mathrm{NO}_{2}{ }^{-} / \mathrm{NO}_{3}{ }^{-}$ levels in the PRE group compared with the CON-P group $(P<0.001)$ (Table 1). $\mathrm{MgSO}_{4}$ therapy caused a significant increase in total $\mathrm{NO}_{2}{ }^{-}$/ $\mathrm{NO}_{3}{ }^{-}$levels in the PRE $+\mathrm{MgSO}_{4}$ group in comparison with the PRE group $(P<0.001)$.

\section{Serum magnesium}

As Table 2 shows, pregnant animals in both the CON-P and the PRE groups had a significant decrease in $\mathrm{Mg}^{+}+$at days 19 and 21 of pregnancy in comparison with the CON-NP group $(P=0.037$ and 0.022 , respectively). However, there was no significant difference between $\mathrm{Mg}^{++}$levels between the CON-P and PRE groups $(P>0.05)$. In contrast, $\mathrm{Mg}^{++}$was significantly increased in the $\mathrm{PRE}+\mathrm{MgSO}_{4}$ group compared with all of the other groups at days 19 and 21 of the study $(P<0.001$ for all $)$.

\section{Angiogenic and antiangiogenic growth factors levels}

Serum VEGF and PlGF. Serum VEGF and PlGF levels of all of the groups in the current study were below the detection limits of the 
Table 1 Systolic $\mathrm{BP}$, proteinuria, urine and serum nitrate/nitrite $\left(\mathrm{uNO} \mathrm{NO}_{2}^{-} / \mathrm{NO}_{3}^{-}, \mathrm{sNO}_{2}^{-} / \mathrm{NO}_{3}^{-}\right.$) levels and $\mathrm{BW}$ of the CON-P, preeclampsia (PRE) and $\mathrm{PRE}+\mathrm{MgSO}_{4}$ groups of rats

\begin{tabular}{|c|c|c|c|c|}
\hline Parameter & Time & $\operatorname{CON}-P(\mathrm{~N}=20)$ & $\operatorname{PRE}(\mathrm{N}=20)$ & $P R E+\mathrm{MgSO}_{4}(\mathrm{~N}=20)$ \\
\hline \multirow[t]{3}{*}{$\mathrm{BP}(\mathrm{mm} \mathrm{Hg})$} & Day 0 & $114.05 \pm 0.68$ & $114.05 \pm 0.75$ & $113.950 \pm 0.94$ \\
\hline & Day 20 & $102.50 \pm 4.43^{*}$ & $157.25 \pm 5.49^{* *, *}$ & $135.60 \pm 4.0^{* *, * * *, *}$ \\
\hline & $\%$ Change & $-10.21 \%$ & $37.91 \%$ & $18.99 \%$ \\
\hline \multirow[t]{2}{*}{ Proteinuria (mg per $18 \mathrm{~h}$ ) } & Day 0 & $4.17 \pm 0.35$ & $4.05 \pm 0.45$ & $4.26 \pm 0.39$ \\
\hline & Day 20 & $4.10 \pm 0.30$ & $17.54 \pm 2.28^{* *, *}$ & $10.31 \pm 1.72^{* *, * * *, *}$ \\
\hline \multirow[t]{2}{*}{ uNO2/NO3 ( $\mu \mathrm{mol}$ per $18 \mathrm{~h}$ ) } & Day 0 & $17.13 \pm 3.71$ & $17.39 \pm 4.09$ & $17.23 \pm 4.06$ \\
\hline & Day 20 & $21.19 \pm 2.92^{*}$ & $17.34 \pm 4.65^{* *}$ & $28.44 \pm 4.67^{* *, * * *, *}$ \\
\hline \multirow[t]{2}{*}{ sNO2/NO3 $\left(\mu \mathrm{moll}^{-1}\right)$} & Day 19 & $68.89 \pm 14.01$ & $37.55 \pm 26.61^{* *}$ & $107.10 \pm 14.74^{* *, * * *}$ \\
\hline & Day 21 & $61.89 \pm 14.14$ & $55.39 \pm 17.00 *$ & $79.88 \pm 22.72^{* *, * * *, *}$ \\
\hline \multirow[t]{2}{*}{ BW (g) } & Day 0 & $252.45 \pm 4.85$ & $254.05 \pm 6.46$ & $252.75 \pm 8.67$ \\
\hline & Day 21 & $315.45 \pm 14.30 *$ & $293.7 \pm 16.44^{* *, *}$ & $310.55 \pm 18.68^{* * *, *}$ \\
\hline
\end{tabular}

Abbreviations: $\mathrm{BP}$, blood pressure; $\mathrm{BW}$, body weight; $\mathrm{CON}-\mathrm{P}$, control pregnant; $\mathrm{PRE}$, pregnant rats with preeclampsia receiving no treatment; $\mathrm{PRE}_{+} \mathrm{MgSO}_{4}$, $\mathrm{MgSO}_{4}$-treated preeclampsia. Data are presented as mean \pm s.d., ${ }^{*} P<0.5$ vs. day $0,{ }^{* *} P<0.05$ vs. CON-P, ${ }^{* * *} P<0.05$ vs. PRE.

Table 2 Serum magnesium $\left(\mathrm{Mg}^{+}+{ }^{+}\right.$), sVEGFR-1 (sFlt-1), VEGFR-2, VEGFR-3 and sENG in the CON-P, preeclampsia (PRE) and PRE + MgSO $_{4}$ groups of rats at day 19 and 21 of pregnancy and of the CON-NP group

\begin{tabular}{|c|c|c|c|c|c|}
\hline Parameters & Time & $C O N-N P(N=10)$ & $C O N-P(N=20)$ & $\operatorname{PRE}(\mathrm{N}=20)$ & $P R E+\mathrm{MgSO}_{4}(\mathrm{~N}=20)$ \\
\hline \multirow[t]{2}{*}{$\mathrm{Mg}^{++}\left(\mathrm{mg} \mathrm{dl}^{-1}\right)$} & Day 19 & $2.16 \pm 0.57$ & $2.08 \pm 0.08^{*}$ & $2.08 \pm 0.08^{*}$ & $3.33 \pm 0.01^{* *, *, * * *}$ \\
\hline & Day 21 & $2.15 \pm 0.56$ & $2.07 \pm 0.09 *$ & $2.07 \pm 0.09 *$ & $3.31 \pm 0.12^{* *, *, * * *}$ \\
\hline \multirow[t]{2}{*}{ sVEGFR-1 (pg ml-1) } & Day 19 & $201.29 \pm 53.14$ & $189.43 \pm 44.73$ & $981.24 \pm 616.05^{* *, *}$ & $213.96 \pm 68.77^{* * *}$ \\
\hline & Day 21 & $201.26 \pm 53.88$ & $188.39 \pm 39.20$ & $291.81 \pm 59.00^{* *, *, \dagger}$ & $220.69 \pm 62.75^{* * *}$ \\
\hline \multirow[t]{2}{*}{ VEGFR-2 (ng ml-1) } & Day 19 & $101.53 \pm 16.81$ & $93.89 \pm 11.17$ & $115.96 \pm 18.87^{* *, *}$ & $106.42 \pm 13.67^{* *, * * *}$ \\
\hline & Day 21 & $102.62 \pm 9.94$ & $96.44 \pm 19.44$ & $90.65 \pm 20.37$ & $111.16 \pm 14.83^{* * * * * *}$ \\
\hline \multirow[t]{2}{*}{ VEGFR-3 (pg ml-1) } & Day 19 & $267.11 \pm 62.59$ & $703.94 \pm 91.23^{*}$ & $965.31 \pm 165.85^{* *, *}$ & $862.29 \pm 212.83^{* *, * * *}$ \\
\hline & Day 21 & $274.25 \pm 50.27$ & $706.94 \pm 74.25^{*}$ & $680.43 \pm 211.76^{*, \dagger}$ & $674.95 \pm 155.6^{*, \dagger}$ \\
\hline \multirow[t]{2}{*}{ sENG } & Day 19 & $3.07 \pm 1.55$ & $5.14 \pm 1.13^{*}$ & $7.85 \pm 1.54^{* *, *}$ & $4.84 \pm 1.42^{* * *, *}$ \\
\hline & Day 21 & $3.19 \pm 1.17$ & $3.87 \pm 0.89 \dagger$ & $7.47 \pm 2.11^{* *, *}$ & $3.97 \pm 1.06 * * *, \dagger$ \\
\hline
\end{tabular}

Abbreviations: $\mathrm{CON}-\mathrm{NP}$, control non-pregnant; $\mathrm{CON}-\mathrm{P}$, control pregnant; $\mathrm{PRE}$, pregnant rats with preeclampsia receiving no treatment; $\mathrm{PRE}+\mathrm{MgSO}_{4}, \mathrm{MgSO}_{4}$-treated preeclampsia; $\mathrm{sENG}$, serum endoglin; sVEGFR, soluble vascular endothelial growth factor receptor-1.

Data are presented as mean \pm s.d., ${ }^{*} P<0.05$ vs. CON-NP, ${ }^{* *} P<0.05$ vs. CON-P, $* * * P<0.05$ vs. PRE, $\dagger P<0.05$ vs. day 19 .

ELISA kits. According to the manufacturer of the VEGF kit, serum VEGF is not detected in normal rats.

Soluble VEGFR-1 (sFlt-1). The PRE group showed a marked increase in serum sFlt-1 levels at day 19 of pregnancy compared with the CON-P group $(P<0.001)$ (Table 2$)$. However, at day 21 of pregnancy, the serum sFlt-1 level of the PRE group showed a significant decrease in comparison with the level at day 19 $(P<0.001)$, but it remained significantly higher than the corresponding value in both the CON-P and CON-NP groups $(P<0.001)$. $\mathrm{MgSO}_{4}$ decreased sFlt-1 levels in the PRE $+\mathrm{MgSO}_{4}$ group at days 19 in comparison with the PRE group $(P<0.001)$. This decreased level was similar to the CON-P and CON-NP groups $(P=0.81$ and 0.92 , respectively). At day 21 of pregnancy, serum sFlt-1 levels were further decreased in the $\mathrm{MgSO}_{4}+\mathrm{PRE}$ group, reaching the CON-P and CON-NP levels $(P=0.54$ and 0.36 , respectively).

Serum ENG (sENG). At day 19 of pregnancy, sENG levels increased significantly in the PRE group in comparison with the CON-P group $(P<0.001)$ (Table 2). However, the $\mathrm{PRE}+\mathrm{MgSO}_{4}$ group showed lower sENG levels than the PRE group $(P<0.001)$, and the PRE + $\mathrm{MgSO}_{4}$ levels showed no difference from the levels in the CON-P group $(P=0.49)$. At day 21 of pregnancy, sENG remained significantly higher in the PRE group compared with the PRE $+\mathrm{MgSO}_{4}$ group $(P<0.001)$, but it decreased significantly in the CON-P and the $\mathrm{PRE}+\mathrm{MgSO}_{4}$ groups, reaching the CON-NP level $(P=0.81$ and 0.22 , respectively).

Morphometric criteria of pups. The number of viable fetuses was significantly lower in the PRE group in comparison with the CON-P group $(P=0.001)$. However, in the $\mathrm{PRE}+\mathrm{MgSO}_{4}$ group, the number of live births showed no significant difference from the CON-P group $(P=0.061)$ (Table 3$)$. The pup mortality rate (calculated as the number of dead fetuses/total number of pups $\times 100)$ was $0 \%$ in the CON-P group, $34.05 \%$ in the PRE group and $17.48 \%$ in the $\mathrm{PRE}+\mathrm{MgSO}_{4}$ group. The number of dead pups was significantly higher in the PRE group in comparison with the CON-P group $(P=0.001) . \mathrm{MgSO}_{4}$ therapy in the $\mathrm{PRE}+\mathrm{MgSO}_{4}$ group decreased the number of dead pups in this group to a comparable level to the CON-P group $(P=0.085)$. Furthermore, Table 3 shows that the total pup weight was significantly lower in the PRE group in comparison to the CON-P group $(P<0.001) . \mathrm{MgSO}_{4}$ therapy increased the total pup weight in the $\mathrm{PRE}+\mathrm{MgSO}_{4}$ group compared with the PRE group $(P=0.028)$, but it remained significantly lower than the CON-P group $(P<0.001)$. Similarly, the untreated PRE group showed decreased single pup weight compared with the CON-P group $(P<0.001) . \mathrm{MgSO}_{4}$ treatment significantly increased the single pup weight in the $\mathrm{PRE}+\mathrm{MgSO}_{4}$ group in comparison with the PRE 
Table 3 Morphometric criteria of pups in the CON-P, preeclampsia (PRE) and PRE $+\mathrm{MgSO}_{4}$ groups of rats at day 21 of pregnancy

\begin{tabular}{lccc}
\hline Parameters & CON-P $(\mathrm{N}=20)$ & $P R E(\mathrm{~N}=20)$ & $P R E+M g S O_{4}(\mathrm{~N}=20)$ \\
\hline Total pups weight (g) & $54.52 \pm 11.55(2.58)$ & $27.96 \pm 16.57(3.7)^{*}$ & $38.25 \pm 14.74(3.29)^{*, * *}$ \\
Single pup weight $(\mathrm{g})$ & $5.95 \pm 1.41(0.31)$ & $3.02 \pm 1.73(0.31)^{*}$ & $4.34 \pm 1.81(0.40)^{*, * *}$ \\
Total pups count & $9.30 \pm 1.55(0.34)$ & $9.25 \pm 2.24(0.50)$ & $9.15 \pm 1.88(0.24)$ \\
Number of live pups & $9.30 \pm 1.55(0.34)$ & $6.1 \pm 4.49(1.00)^{*}$ & $7.55 \pm 1.57(0.35)$ \\
Number of dead pups & $0.00 \pm 0.00$ & $3.15 \pm 4.6(1.02)^{*}$ & $1.6 \pm 1.95(0.43)$ \\
Mortality rate (\%) & 0 & 34.05 & 17.48
\end{tabular}

Abbreviations: $\mathrm{CON}-\mathrm{P}$, control pregnant; $\mathrm{PRE}$, pregnant rats with preeclampsia receiving no treatment; $\mathrm{PRE}+\mathrm{MgSO}_{4}, \mathrm{MgSO}_{4}$-treated preeclampsia. Data are presented as mean \pm s.d., ${ }^{*} P<0.05$ vs. CON-NP, ${ }^{* *} P<0.05$ vs. PRE.

group $(P=0.015)$, but it remained significantly lower than the control group $(P=0.003)$.

\section{Body weight (BW)}

As shown in Table 1, the final BW of the PRE group was significantly lower than the CON-P group $(P<0.001)$. The $\mathrm{MgSO}_{4}$-treated PRE + $\mathrm{MgSO}_{4}$ group showed a final BW that was significantly higher than the PRE group $(P=0.002)$ and comparable to the CON-P rats $(P=0.35)$.

\section{Correlation analysis}

Pearson's correlation analysis revealed a significant positive correlation between serum sFlt-1 and sENG at days 19 and 21 of pregnancy ( $r=0.43, P<0.01 ; r=0.456, P<0.01$, respectively) (Figure 1a and $\mathrm{b}$ ). However, the sENG level at day 19 of pregnancy was negatively correlated with the number of live births $(r=-0.311, P=0.016)$ (Figure 1c) but positively correlated with the number of dead pups $(r=0.26, P=0.04)$ (Figure 2d). Furthermore, sENG levels at days 19 and 21 were negatively correlated with single pup weight $(r=-0.0431, \quad P<0.01$ and $r=-0.473, \quad P<0.001$, respectively) (Figure $2 \mathrm{a}$ and $\mathrm{b}$ ). Correspondingly, sFlt-1 was inversely correlated with the number of live births $(r=-0.42, P=0.042)$ (Figure 1d) and single pup weight $(r=-0.317, P=0.014)$ (Figure $2 \mathrm{c}$ ). At day 19 of pregnancy, serum $\mathrm{NO}_{2}{ }^{-} / \mathrm{NO}_{3}{ }^{-}$levels showed an inverse correlation with sFlt-1 $(r=-0.408, P<0.001)$.

\section{Histopathology of the renal tissue}

Hematoxylin and eosin staining of the renal tissue of the studied groups showed normal histological appearance of the glomeruli and tubules of the CON-NP and CON-P groups (Figure $3 a$ and b). However, glomeruli in the PRE group showed increased cellularity and narrowed capillary lumen and Bowman's capsule in comparison with the CON-NP and CON-P groups (Figure $3 \mathrm{c}$ ). $\mathrm{MgSO}_{4}$ therapy in the $\mathrm{PRE}+\mathrm{MgSO}_{4}$ group markedly abolished the histological changes induced by L-NAME, leading to decreased glomerular cellularity and recovery of the normal appearance of Bowman's capsule and glomerular capillaries (Figure 3d).

\section{DISCUSSION}

Over the past few years, there has been increasing interest in studying the role of angiogenic and antiangiogenic growth factors in the etiology, screening and management of PE. Correspondingly, the current study investigated the effect of $\mathrm{MgSO}_{4}$ therapy on a group of angiogenic and antiangiogenic growth factors in L-NAME-induced PE and the effect on the pregnancy outcome. Circulating antiangiogenic sFlt- 1 and sENG were significantly elevated in the PRE group in the current study. This result was recently attributed to increased placental production and is considered a keystone in the pathophysiology of PE.,18 Elevated sENG predisposes pregnant women to $\mathrm{PE}$ through inhibition of capillary formation, TGF- $\beta$ signaling and TGF- $\beta$-mediated NO synthase activation in endothelial cells. ${ }^{19}$

The undetectable levels of VEGF and PlGF in the pregnant rats in the current study were in agreement with other investigators, who failed to detect these angiogenic factors in a large population of pregnant women regardless of the end result of pregnancy. ${ }^{20-22}$ Furthermore, low PlGF in the presence of high sFlt-1 levels, as observed in the PRE group in the current study, increased the risk of $\mathrm{PE}$ in a prospective nested control study. ${ }^{21}$ The decrease in circulating VEGF and PlGF in PE could be due to decreased placental production. ${ }^{23}$ Moreover, increased sFlt-1 is suggested to bind to these angiogenic factors and decrease their free fractions. ${ }^{18,24}$ Additionally, sFlt-1 competes with VEGFR-2 for VEGF, leading to disturbed angiogenesis, endothelial dysfunction, glomerular damage, impaired glomerular repair and increased apoptosis. ${ }^{17,25}$ These changes contribute to the development of hypertension and proteinuria in PE. ${ }^{10}$ The changes in circulating sFlt-1 correlated positively with sENG at days 19 and 21 of pregnancy (Figure 1a and b). This result was in agreement with other animal and human studies that reported a high correlation between sENG and sFlt1 on one hand and disease severity on the other hand. ${ }^{26,27}$ A causal relationship between these antiangiogenic growth factors and fetal mortality in $\mathrm{PE}$ is strongly suggested by the observed negative correlation between sENG/sFlt-1 and the number of live pups and their birth weight (Figure $1 \mathrm{c}$ and $\mathrm{d}$, Figure $2 \mathrm{a}-\mathrm{c}$ ) and the direct correlation between sENG and the number of dead pups (Figure 2d).

The role of $\mathrm{Mg}^{++}$in the etiology of $\mathrm{PE}$ is still controversial. Unchanged, increased and decreased serum $\mathrm{Mg}^{+}+$levels have been reported in human $\mathrm{PE} .^{28-30}$ These variations were suggested to be due to population heterogeneity or differences in the sample size or assay techniques. In the current study, decreased serum $\mathrm{Mg}^{+}+$was observed in the CON-P and PRE groups in comparison with the CON-NP group. $\mathrm{MgSO}_{4}$ therapy significantly increased $\mathrm{Mg}^{+}+$levels in the $\mathrm{PRE}+\mathrm{MgSO}_{4}$ group compared with the untreated PRE group. The comparable levels of $\mathrm{Mg}^{+}+$in the PRE and CON-P groups suggest that changes in feto-maternal demands and renal hemodynamics during pregnancy rather than PE caused the changes in serum $\mathrm{Mg}^{+}+31$

The introduction of $\mathrm{MgSO}_{4}$ therapy ameliorated the hypertension and proteinuria in the $\mathrm{PRE}+\mathrm{MgSO}_{4}$ group in the current study. Magnesium has in vivo and in vitro vasodilator properties, and $\mathrm{MgSO}_{4}$ injection has been reported to reduce total peripheral resistance and counteract the vasospasm induced by vasoconstrictor substances, such as endothelin-1, in several vascular beds. ${ }^{32}$ This result could explain the preserved normal histological structure and the amelioration of hypertension in the $\mathrm{PRE}+\mathrm{MgSO}_{4}$ group in the current study. Similarly, $\mathrm{MgSO}_{4}$ was able to relieve coronary 

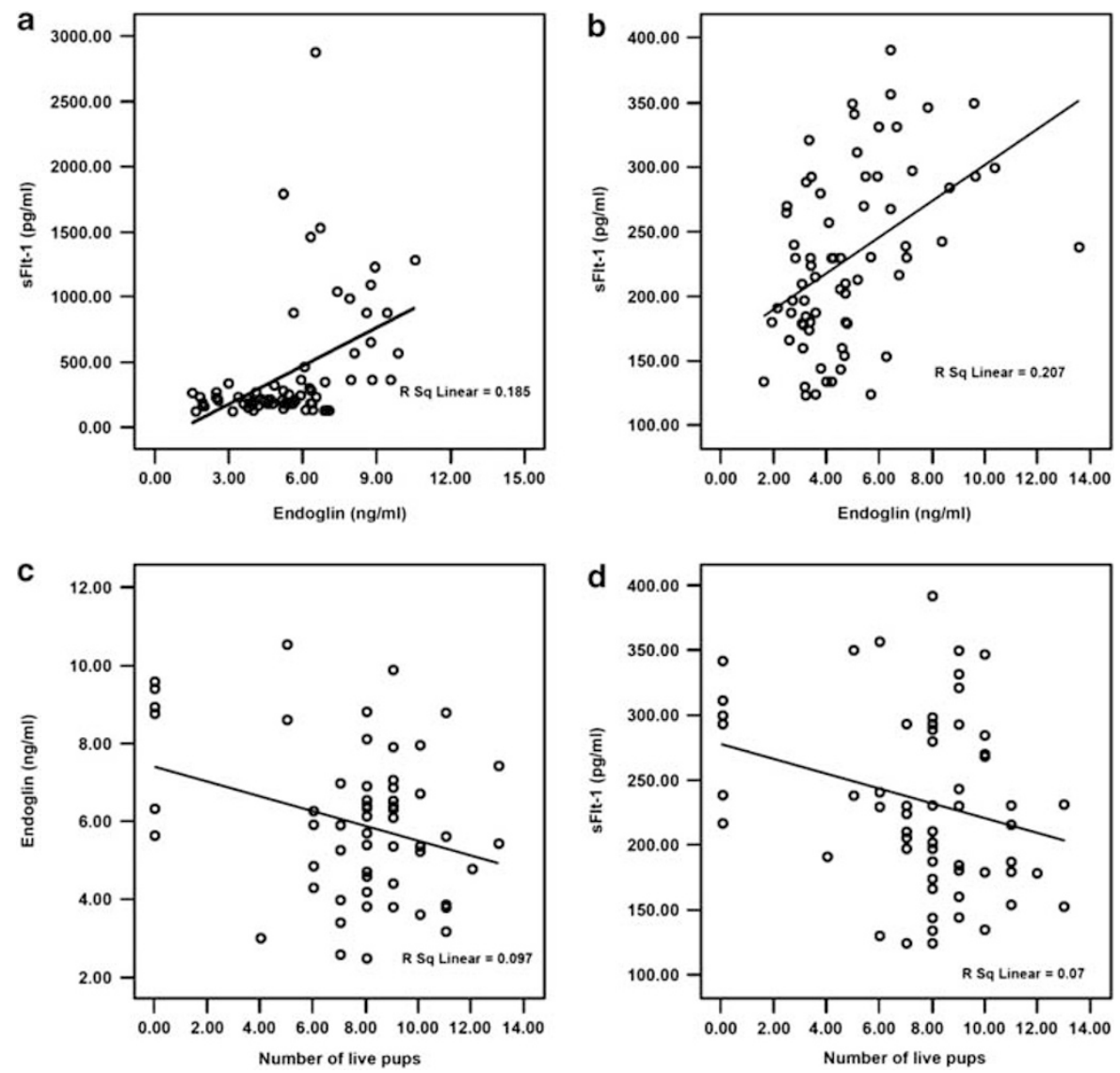

Figure 1 Positive correlation between serum endoglin and sFIt-1 levels at day $19(\mathbf{a}, r=0.43, P<0.01)$ and day $21(\mathbf{b}, r=0.456, P<0.01)$ of pregnancy. The number of live pups is negatively correlated with serum endoglin level at day 19 (c, $r=-0.311, P=0.016)$ and sFlt- 1 level at day 21 of pregnancy (d, $r=-0.42, P=0.042$ ).

vasospasms, increase blood flow and improve endothelial function, leading to a good response in several ischemic cardiac problems. ${ }^{17,33}$ Similarly, $\mathrm{MgSO}_{4}$ inhibits cerebral vasospasms and prevents seizures in patients with severe PE. ${ }^{34}$ Other antihypertensive drugs, such as clonidine, diazoxide, frusemide and hydralazine, show no effect on the production of sFlt-1 and sENG from the placentas of patients with PE. ${ }^{35}$ This study, however, demonstrated the inhibitory effect of $\mathrm{MgSO}_{4}$ therapy on serum levels of antiangiogenic growth factors and its ability to increase $\mathrm{NO}$ metabolic end products in the serum and urine of the $\mathrm{PRE}+\mathrm{MgSO}_{4}$ group. Although there is no clear explanation of this increase in $\mathrm{NO}$ production, both direct and indirect pathways could be hypothesized. $\mathrm{MgSO}_{4}$ might directly stimulate NO synthase activity or indirectly stimulate NO release through VEGF. ${ }^{36,37}$ The latter suggestion is supported by the observed inverse correlation between NO metabolites and sFlt-1 levels in the current study. This gives the impression that decreased availability of VEGF due to its binding with sFlt-1 might decrease VEGF-enhanced $\mathrm{NO}$ production ${ }^{38}$ and vice versa. Additionally, the protective effect of $\mathrm{MgSO}_{4}$ on the renal structure observed in histopathology may preserve renal NO production in the treated group. However, further studies are needed to clarify the mechanism of this increase in $\mathrm{NO}$ production in $\mathrm{MgSO}_{4}$-treated $\mathrm{PE}$ rats.

The increase in VEGFR-2 and VEGFR-3 levels observed in the PRE group in the current study (Table 2) may be secondary to the decreased availability of VEGF, which increases the free unbound receptors in serum. ${ }^{39}$ However, decreased VEGFR-2 and VEGFR-3 in the $\mathrm{MgSO}_{4}$-treated group could be related to the decrease in sFlt-1, which increases the free unbound forms of VEGF and PlGF, making them more available to bind to other receptors, such as VEGFR-2 and VEGFR-3. Binding of VEGF to its functional receptors will help it to induce NO and vasodilatory prostacyclins in endothelial cells, leading to decreased vascular tone and $\mathrm{BP}^{36,37}$ In this case, VEGF works in association with NO to maintain normal structure and function of the glomerular basement membrane, ${ }^{40}$ stimulate glomerular repair, and inhibit proteinuria. ${ }^{41}$ This pathway could explain the amelioration of proteinuria and hypertension in the $\mathrm{PRE}+\mathrm{MgSO}_{4}$ group in the current study. Additionally, the vasodilatory effect of $\mathrm{NO}$ may augment the inhibitory effect of $\mathrm{MgSO}_{4}$ on the vascular tone and peripheral vascular resistance, leading to decreased $\mathrm{BP}$ and increased renal blood flow. ${ }^{28}$

In addition, the NO signaling pathway, the vasodilator and antiplatelet effects of $\mathrm{NO}$ are expected to decrease vascular tone and increase placental blood flow, leading to better fetal nutrients and oxygen supply. ${ }^{42}$ This expectation explains the increased fetal viability and birth weight in the $\mathrm{MgSO}_{4}$-treated group. The reduction of circulating antiangiogenic factors in the $\mathrm{PRE}+\mathrm{MgSO}_{4}$ group in the current study could be explained by the ability of $\mathrm{MgSO}_{4}$ to decrease systemic vascular resistance and counteract the vasoconstrictor substances in several vascular beds. ${ }^{28}$ Furthermore, $\mathrm{MgSO}_{4}$ was reported to decrease feto-placental perfusion pressure ${ }^{43}$ and depress the expression of caspase- 3 in the placenta. ${ }^{44}$ These effects are anticipated to improve placental blood flow and relieve the 

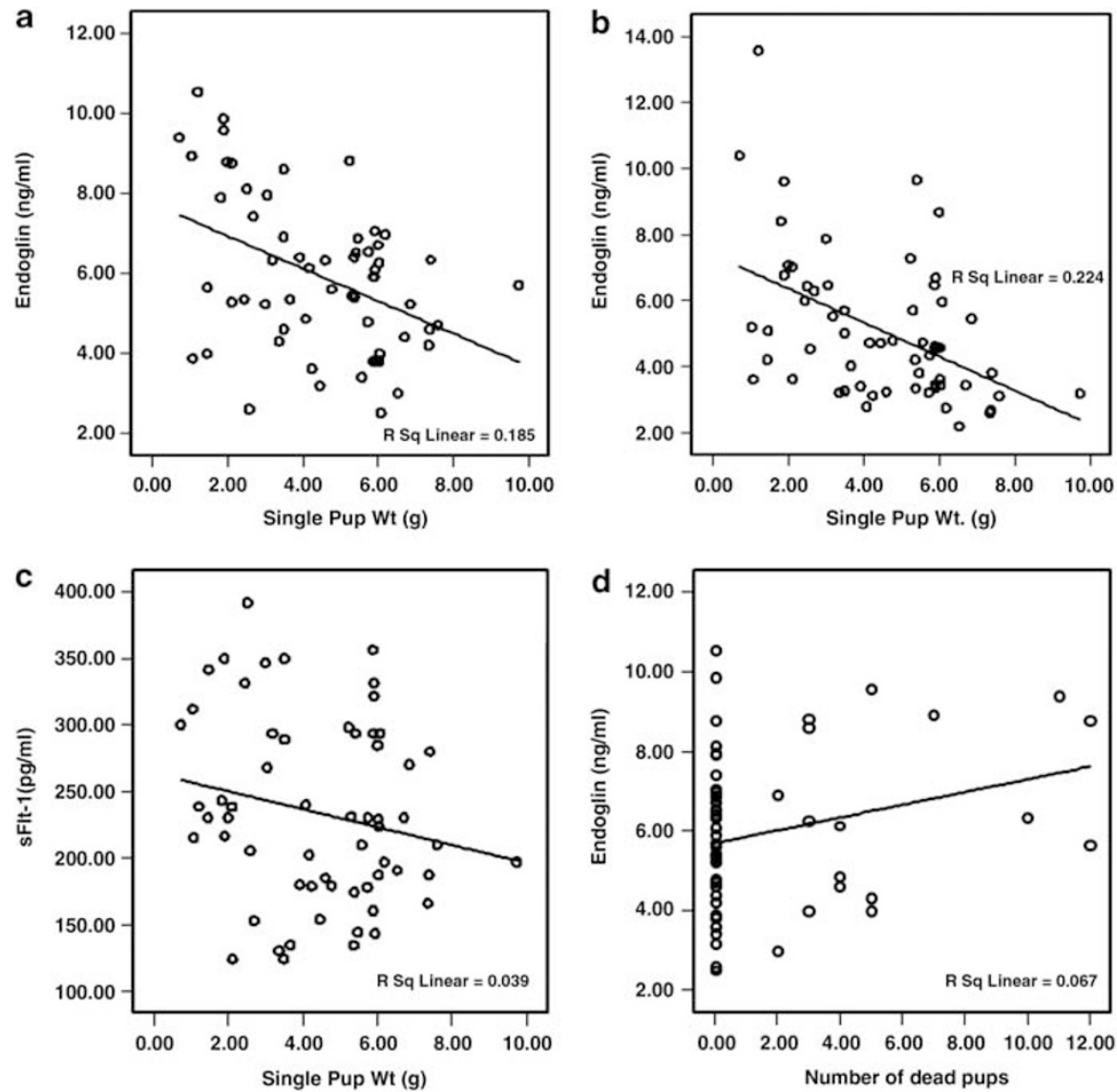

Figure 2 Single pup weight is negatively correlated with serum endoglin level at days 19 and 21 (a, $r=-0.0431, P<0.01$ and $\mathbf{b}, r=-0.473, P<0.001$ ) and sFlt-1 levels at day 19 (c, $r=-0.317, P=0.014$ ). (d) Positive correlation between serum endoglin and the number of dead pups $(r=0.26, P=0.04)$.
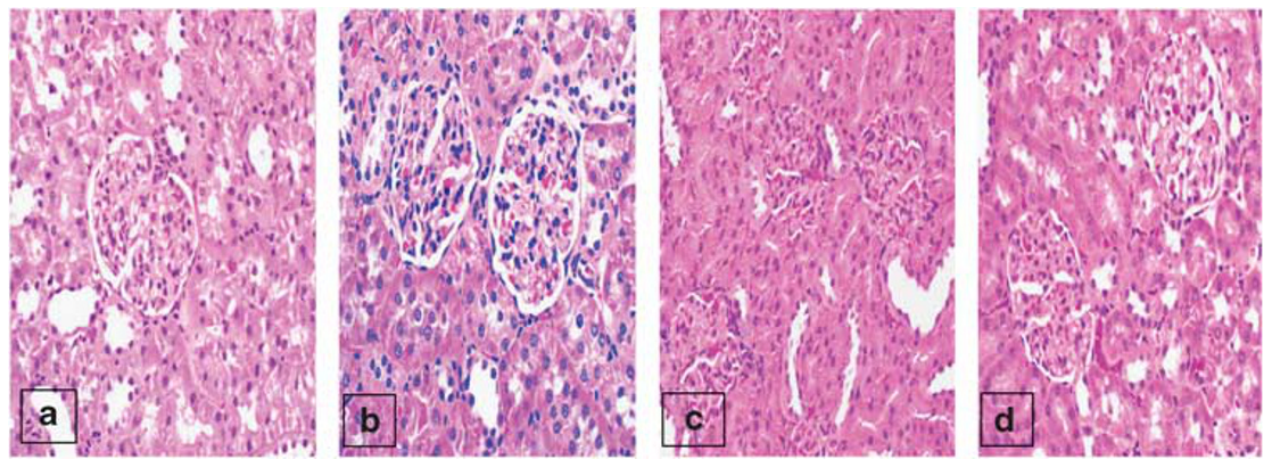

Figure 3 Hematoxylin and eosin $(\times 40)$ staining of the kidney tissue of the studied groups revealed normal appearance of the glomeruli and tubules in the CON-NP and CON-P groups (a, b). The PRE group showed crowded glomeruli with hypercellularity and narrow capillary lumen and Bowman's capsule (c). $\mathrm{MgSO}_{4}$ therapy in the PRE $+\mathrm{MgSO}_{4}$ group abolished the glomerular changes induced by L-NAME (d).

ischemia and subsequently decrease the production of sFlt-1 and ENG. ${ }^{45}$ Enhanced placental circulation is likely to support its physiological functions, leading to better fetal nutrition, as reflected in fetal birth weight and viability. ${ }^{4}$

We found an inverse relationship between sFlt- 1 and $\mathrm{NO}_{2}{ }^{-} / \mathrm{NO}_{3}{ }^{-}$ in the current study. This result suggests that the factors that increase sFlt-1 may concurrently decrease NO production, producing vasoconstriction and increasing vascular resistance through these two opposite effects, which start the pathophysiological process of PE.
We conclude that $\mathrm{MgSO}_{4}$ is thus a promising compound that has a mechanistic role in the inhibition of the pathophysiological process of $\mathrm{PE}$. The vasodilatory effect of $\mathrm{MgSO}_{4}$ may be the primary mechanism of action that preserves placental circulation and protects it against ischemia and hypoperfusion. This effect inhibits the production of antiangiogenic growth factors. Second, $\mathrm{MgSO}_{4}$ augments NO production and maintains the balance between angiogenic and antiangiogenic growth factors, which is essential for the normal growth and development of the feto-placental unit. 


\section{ACKNOWLEDGEMENTS}

I thank King Abdul-Aziz City for Science and Technology (KACST), Kingdom of Saudi Arabia, Riyadh, General Directorate of Research Grants Programs for supporting this research (grant number LGP-14-16). I also express my gratitude to Dr Maha Arafa for her help in the pathological examination of the kidney tissue in the study. I thank the technicians and workers in the animal house and the physiology department laboratory of the College of Medicine King Saud University for their help and assistance during the experimental part of the study.

1 Roberts JM, Pearson G, Cutler J, Lindheimer M. Summary of the NHLBI Working Group on Research in Hypertension During Pregnancy. Hypertension 2003; 41: 437-445.

2 WHO. Global Burden of Disease for the Year 2001 by World Bank Region, for Use in Disease Control Priorities in Developing Countries. National Institutes of Health, Bethesda, MD, 2004

3 WHO. Make Every Mother and Child Count. In: World Health Report. World Health Organization, Geneva, 2005

4 Chaiworapongsa T, Romero R, Kim YM, Kim GJ, Kim MR, Espinoza J, Bujold E, Gonçalves L, Gomez R, Edwin S, Mazor M. Plasma soluble vascular endothelial growth factor receptor-1 concentrations elevated prior to the clinical diagnosis of pre-eclampsia. J Matern Fetal Neonatal Med 2005; 17: 3-18.

5 Silasi M, Cohen B, Karumanchi SA, Rana S. Abnormal placentation, angiogenic factors, and the pathogenesis of preeclampsia. Obstet Gynecol Clin North Am 2010; 37: 239-253.

6 Steinberg G, Khankin EV, Karumanchi SA. Angiogenic factors and preeclampsia. Thromb Res 2009; 123: S93-S99.

7 Levine RJ, Maynard SE, Qian C, Lim KH, England LJ, Yu KF, Schisterman EF, Thadhani R, Sachs BP, Epstein FH, Sibai BM, Sukhatme VP, Karumanchi SA Circulating angiogenic factors and the risk of preeclampsia. N Engl J Med 2004; 350: 672-683.

8 Clark's DE, Smith SK, He Y, Day KA. Vascular endothelial growth factor antagonist is produced by the human placenta and released into the maternal circulation. Biol Reprod 1998; 59: 1540-1548.

9 Lyall F, Greer IA, Boswell F, Fleming R. Suppression of serum vascular endothelial growth factor immunoreactivity in normal pregnancy and in preeclampsia. $\mathrm{Br}$ Obstetrics Gynecol 1997; 104: 223-228.

10 Traquilli AL, Bezzeccheri V, Giannubilo SR. Amniotic vascular endothelial growth factor (VEGF) and nitric oxide (NO) in women with subsequent preeclampsia. Eur J Obstet Gynecol Reprod Biol 2004; 113: 17-20.

11 Matsubara K, Matsubara Y, Hyodo S, Katayama T, Ito M. Role of nitric oxide and reactive oxygen species in the pathogenesis of preeclampsia. J Obstet Gynaecol Res 2010; 36: 239-247.

12 El Salahy EM, Ahmed MI, EL-Gharieb A, Tawfik H. New scope in angiogenesis: role of vascular endothelial growth factor (VEGF), NO, lipid peroxidation, and vitamin E in the pathophysiology of pre- eclampsia among Egyptian females. Clin Biochem 2001; 34 323-329.

13 Duley L, Henderson-Smart D. Magnesium sulfate versus phenytoin for eclampsia. Cochrane Database Syst Rev 2003, CD000128.

14 de Moura RS, Resende AC, Moura AS, Maradei MF. Protective action of a hydroalcoholic extract of a vinifera grape skin on experimental preeclampsia in rats. Hypertens Pregnancy 2007; 26: 89-100.

15 Coates BJ, Broderick TL, Batia LM, Standley CA. $\mathrm{MgSO}_{4}$ prevents left ventricular dysfunction in an animal model of preeclampsia. Am J Obstet Gynecol 2006; 195: 1398-1403.

16 Green LC, Wanger DA, Glogowski J, Skipper PL, Wishnok JS, Tannenbaum SR. Analysis of nitrate\&nitrite and (15N) nitrate in biological fluids. Anal Biochem 1982; 126: $131-138$.

17 Maynard SE, Min JY, Merchan J, Lim KH, Li J, Mondal S, Libermann TA, Morgan JP, Sellke FW, Stillman IE, Epstein FH, Sukhatme VP, Karumanchi SA. Excess placental soluble fms-like tyrosine kinase 1 (sFlt1) may contribute to endothelial dysfunction, hypertension, and proteinuria in preeclampsia. J Clin Invest 2003; 111: 649-658.

18 Vuorela P. Amniotic fluid- soluble vascular endothelial growth factor receptor-1 in preeclampsia. Obestet Gynecol 2000; 95: 353-357.

19 Luft F. Soluble endoglin (sEng) joins the soluble fms-like tyrosine kinase (sFlt) receptor as a pre-eclampsia molecule. Nephrol Dial Transplant 2006; 21 : 3052-3054

20 Helske S, Vuorela P, Carpen O, Horing C, Weich H, Halmeshmaki E. Expression of vascular endothelial growth factors 1,2 , and3 in placentas from normal and complicated pregnancies. Mol Hum Reprod 2011; 7: 205-210.
21 Thadhani R, Mutter W, Wolf M, Levine R, Taylor R, Sukhatme V, Ecker J, Karumanchi S. First trimester placental growth factor and soluble Fms-like tyrosine kinase 1 and risk for preeclampsia. J Clin Endocrinol Metab 2004; 89: 770-775.

22 Romero R, Nien JK, Espinoza J, Todem D, Fu W, Chung H, Kusanovic JP, Gotsch F, Erez O, Mazaki-tovi S, Gomez R, Edwin S, Chaiworapongsa T, Levine RJ, Karumanchi A. A longitudinal study of angiogenic (placental growth factor) and anti-angiogenic (soluble endoglin and soluble VEGF receptor-1) factors in normal pregnancy and patients destined to develop preeclampsia and deliver a small-for-gestational-age neonate. J Matern Fetal Neonatal Med 2008; 21: 9-23.

23 Reuvekamp A, Velsing-Aarts FV, Poulina IE, Capello JJ, Duits AJ. Selective deficit of angiogenic growth factors characterizes pregnancies complicated by pre-eclampsia. $\mathrm{Br}$ J Obstet Gynaecol 1999; 106: 1019-1022.

24 Hornig C, Barleon B, Ahmad S, Vuorela P, Ahmed A, Weich HA. Release and complex formation of soluble VEGFR1 from endothelial cells and biological fluids. Lab Invest 2000; 80: 443-454.

25 Autiero M, Luttun A, Tjwa M, Carmeliet P. Placental growth factor and its receptor, vascular endothelial growth factor receptor-1: novel targets for stimulation of ischemic tissue revascularization and inhibition of angiogenic and inflammatory disorders. J Thromb Haemost 2003; 1: 1356-1370.

$26 \mathrm{Kim}$ YN, Lee DS, Jeong DH, Sung MS, Kim KT. The relationship of the level of circulating antiangiogenic factors to the clinical manifestations of preeclampsia. Prenat Diagn 2009; 29: 464-470

27 Aggarwal PK, Chandel N, Jain V, Jha V. The relationship between circulating endothelin-1, soluble fms-like tyrosine kinase-1 and soluble endoglin in preeclampsia. J Hum Hypertens 2012; 26: 236-241.

$28 \mathrm{Zhao} \mathrm{F}$. Ca, Mg, Cu and $\mathrm{Zn}$ contents of the maternal and umbilical cord serum in pregnancy-induced hypertension. Zhonghua Fu Chan Ke Za Zhi 1989; 24: 212-214.

29 Sanders R, Konijnenberg A, Huijgen HJ, Wolf H, Boer K, Sanders GT. Intracellular and extracellular, ionized and total magnesium in pre-eclampsia and uncomplicated pregnancy. Clin Chem Lab Med 1999; 37: 55-59.

30 Sukonpan K, Phupong V. Serum calcium and serum magnesium in normal and preeclamptic pregnancy. Arch Gynecol Obstet 2005; 273: 12-16.

31 Standley CA, Whitty JE, Mason BA, Cotton DB. Serum ionized magnesium levels in normal and preeclamptic gestation. Obstet Gynecol 1997; 89: 24-27.

32 Kemp PA, Gardinerm SM, March JE, Rubin PC, Bennett T. Assessment of the effects of endothelin-1 and magnesium sulfate on regional blood flows in conscious rats, by the coloured microsphere reference technique. Br J Pharmacol 1999; 126: 621-626.

33 Woods KL, Fletcher F, Roffe C, Haider Y. Intravenous magnesium sulfate in suspected acute myocardial infarction: results of the second leicester intravenous magnesium intervention trial (LIMIT-2). Lancet 1992; 339: 1553-1558.

34 Omu AE, Al-Harmi J, Vedi HL, Mlechkova L, Sayed AF, Al-Ragum NS. Magnesium sulfate therapy in women with pre-eclampsia and eclampsia in Kuwait. Med Princ Pract 2008; 17: 227-232.

35 Xu B, Thornton C, Tooher J, Ogle R, Lim S, Makris A, Hennessy A. Effects of antihypertensive drugs on production of soluble fms-like tyrosine kinase 1 and soluble endoglin from human normal and pre-eclamptic placentas in vitro. Clin Exp Pharmacol Physiol 2009; 36: 839-842.

36 Connolly DT, Heuvelman DM, Nelson R, Olander JV. Tumour vascular permeability factor stimulates endothelial cell growth and angiogenesis. J Clin Invest 1989; 84: 1470-1478

37 Morbidelli L, Chang CH, Douglas JG, Granger HJ, Ledda F, Ziche M. Nitric oxide mediates mitogenic effect of VEGF on coronary vascular endothelium. Am J Physiol 1996; 270: H411-H415.

$38 \mathrm{He} \mathrm{H}$, Venema VJ, X GU, Venema RC, Marrero MB, Caldwell RB. Vascular endothelial growth factor signals endothelial cell production of nitric oxide and prostacyclin through flk-1/KDR activation of c-Src. J Biol Chem 1999; 274: 25130-25135.

39 Moore Simas TA, Crawford SL, Solitro MJ, Frost SC, Meyer BA, Maynard SE. Angiogenic factors for the prediction of preeclampsia in high-risk women. Am J Obstet Gynecol 2007; 197: 244.e1-244.e8.

40 Shaamash AH, Elsonosy ED, Zakhari MM, Radwan SH, El-Deien HM. Placental nitric oxide synthase (NOS) activity and nitric oxide (NO) production in normal pregnancy, pre-eclampsia and eclampsia. Int J Gynecol Obstet 2001; 72: 127-133.

41 Ostendorf T. VEGF (165) mediates glomerular endothelial repair. J Clin Biol Chem 1999; 104: 913-923.

42 Nobunaga T, Tokugawa Y, Hashimoto K. Plasma nitric oxide levels in pregnant patients with preeclampsia and essential hypertension. Gynecol Obest Invest 1996; 41: 189-193.

43 Kovac CM, Howard BC, Pierce BT, Hoeldtke NJ, Calhoun BC Napolitano PG. Fetoplacental vascular tone is modified by magnesium sulfate in the preeclamptic ex vivo human placental cotyledon. Am J Obstet Gynecol 2003; 189: 839-842.

$44 \mathrm{Gao} \mathrm{H}$, Zou L. Effect of magnesium sulfate on fetal rats of fetal growth retardation and its relation with expression of caspase- 3 on the placenta of maternal rat. Zhonghua Fu Chan Ke Za Zhi 2006; 41: 525-528.

45 Millauer B, Wizigmann-Voos S, Schnurch $H$, Martinez R. High affinity VEGF binding and developmental expression suggest FLK-1 as a major regulator of vasculogenesis and angiogenesis. Cell 1993; 72: 835-846. 